\title{
Erratum to: Effect of Al-5Ti-1B-1Re on the Microstructure and Hot Crack of As-Cast Al-Zn-Mg-Cu Alloy
}

H.J. Wang, J. Xu, Y.L. Kang, M.O. Tang, and Z.F. Zhang

\section{Erratum to: J. of Materi Eng and Perform DOI 10.1007/s11665-013-0860-0}

In the paper titled "Effect of Al-5Ti-1B-1Re on the microstructure and hot crack of as-cast $\mathrm{Al}-\mathrm{Zn}-\mathrm{Mg}-\mathrm{Cu}$ alloy", Ref 24 was not cited in the figure title of Fig.10: DSC curve of Al-5Ti-1B-1Re master alloy. This has been corrected in this erratum.

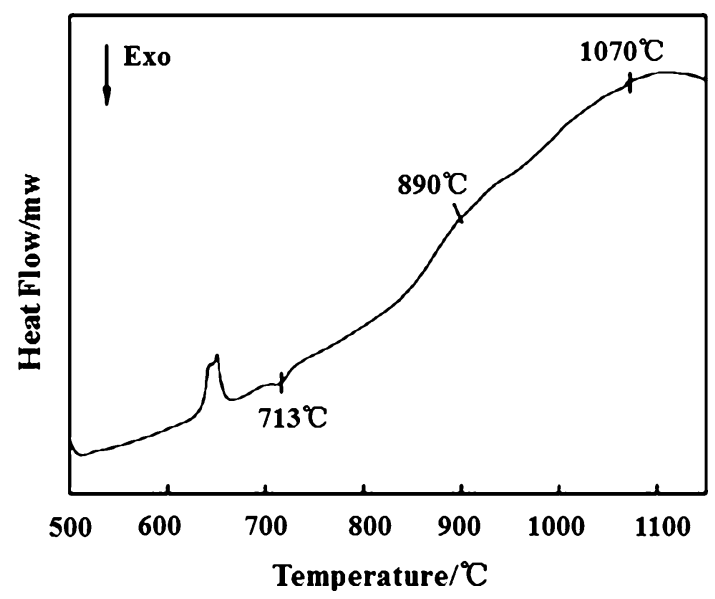

Fig. 10 DSC curve of Al-5Ti-1B-1Re master alloy (Ref 24)

The online version of the original article can be found under doi:10.1007/s11665-013-0860-0.

H.J. Wang, General Research Institute for Non-Ferrous Metals, Beijing 100088, China; and School of Materials Science and Engineering, University of Science and Technology Beijing, Beijing 100083, China; J. Xu, M.O. Tang, and Z.F. Zhang, General Research Institute for Non-Ferrous Metals, Beijing 100088, China; and Y. L. Kang, School of Materials Science and Engineering, University of Science and Technology Beijing, Beijing 100083, China. Contact e-mail: hjwang606@gmail.com. 